\title{
Heat and mass transfer of combusting monodisperse droplets in a linear stream
}

\author{
G. Castanet, M. Lebouché, F. Lemoine* \\ ENSEM, Laboratoire d'energetique et de macanique theorique et appliquee (LEMTA)—CNRS UMR 7563, \\ 2 Avenue de la Forêt de Haye, BP 160, F-54504 Vandouvre-les-Nancy Cedex, France
}

\begin{abstract}
Heat and mass transfer phenomena in fuel sprays is a key issue in the field of the design of the combustion chambers where the fuel is injected on a liquid form. The development and validation of new physical models related to heat transfer and evaporation in sprays requires reliable experimental data. This paper reports on an experimental study of the energy budget, i.e. internal flux, evaporation flux and convective heat flux for monodisperse combusting droplets in linear stream. The evaporation flux is characterized by the measurement of the droplet size reduction by the phase Doppler technique, and the droplet mean temperature, required for the internal and convective heat flux evaluation, is determined by two-color, laser-induced fluorescence. The Nusselt and Sherwood numbers are evaluated from the heat and mass fluxes estimation, as a function of the inter-droplet distance. The results are compared to physical models available in the literature, for moving, evaporating and isolated droplets. A correction factor of the isolated droplet model, taking into account drop-drop interaction on the Sherwood and Nusselt numbers, is proposed.
\end{abstract}

Keywords: Laser-induced fluorescence; Droplet; PDA; Evaporation; Monodisperse droplet stream; Spray combustion; Nusselt number; Sherwood number

\section{Introduction}

Computation of modern combustion chambers of aero-engines and automotive direct injection engines, where the fuel is injected as a liquid spray, requires a reliable description of the heat and mass transfer para- meters. When a fuel droplet enters a high temperature environment like in a combustion chamber, the droplet is heated, evaporates and finally the fuel vapor burns, delivering the energy for propulsion. Evaporation and combustion models of isolated, stagnant or moving fuel droplets are widely available in the literature ([1], [2] and [3], [4]). Particularly, the effect of the thermal radiation on the evaporation rate of single droplets was analyzed by Elperin and Krasovitov [5].

Improving the knowledge of the heat and mass transfer phenomena between the liquid droplet and its hot surrounding gaseous phase is a key issue to understand the highly complex phenomena occurring in spray 


$\begin{array}{ll}\text { Nomenclature } \\ a & \text { thermal diffusivity } \\ B_{\mathrm{M}} & \text { mass transfer Spalding number } \\ B_{\mathrm{T}} & \text { thermal transfer Spalding number } \\ C & \text { non-dimensional distance parameter } \\ C_{\mathrm{p}} & \text { specific heat } \\ D & \text { droplet diameter } \\ D_{\mathrm{g}} & \text { molecular diffusivity of the ethanol vapor } \\ L e & \text { Lewis number } \\ L_{\mathrm{V}} & \text { liquid fuel latent heat of vaporization } \\ m & \text { droplet mass } \\ \dot{m} & \text { fuel vapor flowrate } \\ N u & \text { Nusselt number } \\ P r & \text { Prandtl number } \\ Q_{\mathrm{L}} & \text { heat flux entering into the droplet } \\ P & \text { pressure } \\ R e & \text { droplet Reynolds number } \\ S & \text { droplet surface } \\ S h & \text { Sherwood number } \\ S c & \text { Schmidt number } \\ T & \text { temperature } \\ T_{\mathrm{m}} & \text { mean droplet temperature } \\ t & \text { time } \\ U_{\mathrm{S}} & \text { maximum surface velocity }\end{array}$

\section{Nomenclature}

a thermal diffusivity

$B_{\mathrm{M}} \quad$ mass transfer Spalding number

$B_{\mathrm{T}} \quad$ thermal transfer Spalding number

$C_{\mathrm{p}} \quad$ specific heat

$D \quad$ droplet diameter

$D_{\mathrm{g}} \quad$ molecular diffusivity of the ethanol vapor

$m \quad$ droplet mass

$\dot{m} \quad$ fuel vapor flowrate

$\mathrm{Nu} \quad$ Nusselt number

$\mathrm{Pr} \quad$ Prandtl number

$Q_{\mathrm{L}} \quad$ heat flux entering into the droplet

Re droplet Reynolds number

$S \quad$ droplet surface

Sh Sherwood number

Sc Schmidt number

$T$ temperature

$t$
$V \quad$ droplet velocity

$Y_{\mathrm{K}} \quad$ fuel vapor mass fraction

Greek symbols

$\Phi_{\mathrm{C}} \quad$ convective heat flux

$\Phi_{\text {vap }} \quad$ vaporization heat flux

$\lambda$ thermal conductivity

$\mu \quad$ dynamic viscosity

$\rho \quad$ specific density

\section{Subscripts}

amb ambient conditions in the flame

eq equilibrium

g gas phase

iso isolated droplet

i injection

1 fuel liquid phase

ref reference state

Ox oxidizer

$\infty \quad$ conditions far away from the flame front in quiescent air

$0 \quad$ first point of measurement just after the exit of the ignition device combustion. One of the main difficulties is related to the constant variation of the physical properties of the gaseous phase, due to the change in its composition and temperature. Another difficulty is that the droplet-todroplet interactions are not well taken into account. These interaction phenomena are highly important near the fuel injection devices, where the droplet density is high. Sangiovanni and Labowsky [6] have shown, using a monodisperse droplet line injected in a combustion chamber, the influence of the inter-droplet distance on the ignition time as well as on the diameter regression law. Brzustowski et al. [7] analyzed the combustion of two stagnant interacting droplets by solving Laplace's equation and using qualitative experiments. Both the burning rate of each droplet and the shape of the flame were investigated: the burning rate was found to be smaller than that of an isolated droplet of the same size. More theoretical work was performed by Labowsky [8] or Marberry et al. [9], who developed a generalized treatment for burning rates of motionless droplets in finite arrays containing up to eight symmetrically arranged monodisperse droplets using the point sources method. Particle interactions were shown to be a function of particle size, number density and geometry of the array. Correction factors from which multiple particle burning rates can be calculated from single particle burning rates were established.
Generally speaking, the increase of droplet density tends to decrease the droplet drag coefficient and the vaporization rate. The heat transfer by forced convection is also influenced and modified by the interaction phenomena. Chiang and Sirignano [10] have investigated numerically the case of two vaporizing droplets moving in tandem, by taking into account the forced convection of the gas phase, the transient deceleration due to the drag force, the surface regression, the respective motion between the two droplets, the liquid phase internal circulation, the transient heating of the liquid phase and variable physical properties. The dependencies of the transfer numbers (i.e. Nusselt and Sherwood numbers) on initial droplet Reynolds number, initial droplet spacing, initial droplet size ratio, physical properties were considered. An extension of this study to the system of three droplets in a linear stream is presented by the same authors [11]. More recently, experimental results were obtained by Castanet et al. [12] on a monodisperse ethanol droplet stream, injected in the thermal boundary layer of a vertical heated plate. The droplet size reduction was measured by a light scattering technique simultaneously with the droplet temperature determined using a two-color laser-induced fluorescence technique. The convective heat transfer coefficient as well as the Nusselt number was inferred from the overall energy budget of the droplet in its gaseous surroundings: 
the influence of the inter-droplet distance, characterizing the interaction regime, was clearly highlighted. However this study was not related to the case of combusting droplet. The development of correlations that are able to describe adequately heat and mass transfer phenomena in the presence of droplet-to-droplet interactions is fundamental. Experimental data must be collected in basic experiments, where the time evolutions of the different parameters (i.e. droplet size, temperature, velocity, droplet spacing) can be easily separated. In the present study, the case of combusting single-component (ethanol) droplets in linear stream is considered. The energy budget equation shows that the experimental characterization of the evolution of the droplet temperature and droplet mass as a function of time are the critical parameters. In this study, the droplet diameter evolution has been measured by an optimized phase Doppler technique and the temperature by the two-color laser-induced fluorescence technique [13,14].

Both Sherwood and Nusselt numbers will be characterized as functions of the usual non-dimensional numbers (i.e. Reynolds, Schmidt, Prandtl, Spadling and Lewis) and the non-dimensional distance parameter characterizing the droplet to droplet interactions.

\section{Combusting monodisperse droplet stream facilities}

A linear monodisperse droplet stream is generated by Rayleigh disintegration of a liquid jet, using of a mechanical vibration of the liquid column obtained by a piezoceramic actuator. The applied voltage on the actuator determines the position of the break-up zone of the jet depending also on the fuel physical properties, which are in turn related to the injection temperature.

For certain frequencies, the liquid jet breaks up into equally spaced and monosized droplets at the frequency of the forced mechanical vibration. The liquid fuel is pressurized with compressed air between 0.2 and 1 bars and is forced through a calibrated orifice of $\Phi_{0}=50 \mu \mathrm{m}$ in diameter. According to the Rayleigh theory, the resulting droplet diameter is about $1.9 \Phi_{0}$. The droplet injection velocity can range from $2 \mathrm{~m} / \mathrm{s}$ to about 10 $\mathrm{m} / \mathrm{s}$. The fuel can be pre-heated in the injector body by means of an externally heated water circulation. The temperature of the fuel is measured exactly at the injection point with the use of a K-type thermocouple. An electrically heated coil allows initiation of the combustion just after the break-up zone of the liquid jet and a laminar diffusion flame appears (Fig. 1).

The droplet have been visualized using a CCD camera equipped with a high magnification lens, under a rapid stroboscopic lighting to fix the droplets on the image. These observations underlined that the droplets are not completely spherical after the break-up zone but seem to oscillate around the spherical shape. However, the droplets recover the spherical shape about $10 \mathrm{~mm}$ after the injector exit. Generally, the measurement zone begins about $30-50 \mathrm{~mm}$ after the injector exit, because of

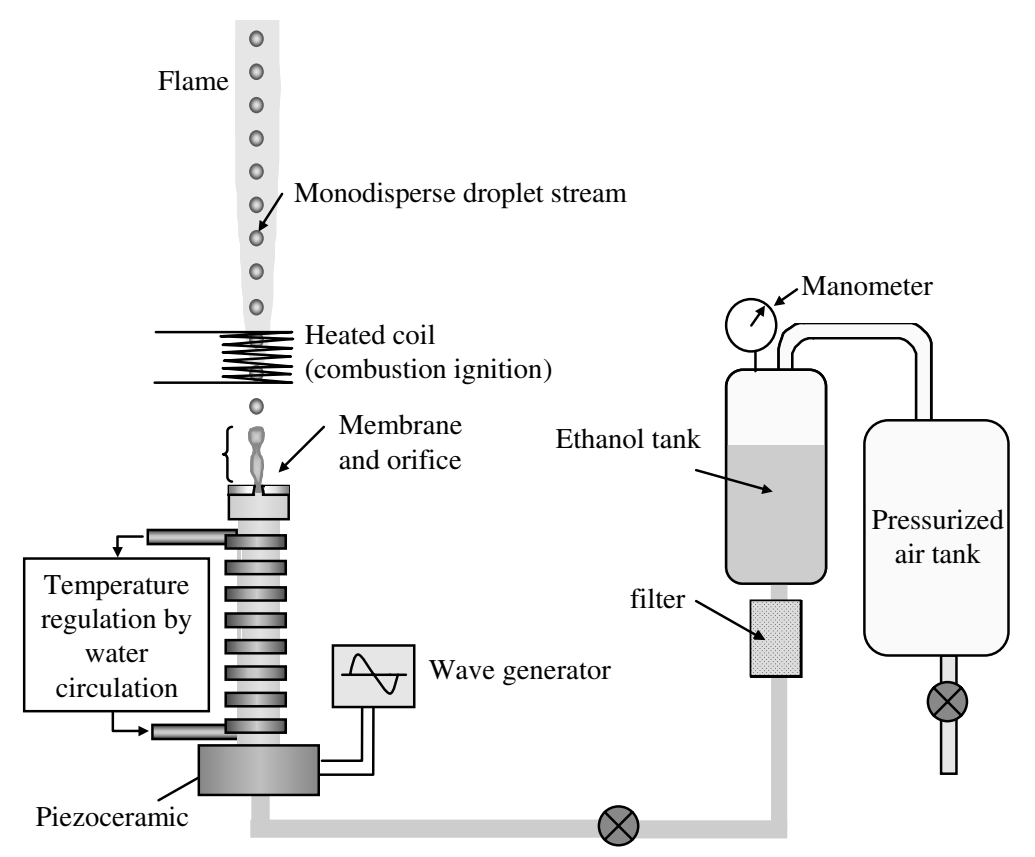

Fig. 1. Experimental arrangement. 
the presence of the igniter and possibly the electrostatic deviator, which is highly sufficient to have spherical droplets, allowing the phase Doppler to operate properly.

In order to characterize the effects of dropletto-droplet interactions, the non-dimensional distance parameter is introduced. This parameter corresponds to the ratio between the inter-droplet spacing $L$ and the droplet diameter $D$ :

$C=L / D$

By modifying the fuel flowrate and the frequency of the piezoceramic vibration, the distance between droplets can be changed independently of the droplet diameter. The frequency range corresponding to a monodisperse jet of droplets is narrow and allows a limited range of distance parameters to be reached. A technique of electrostatic deviation of the droplet has therefore been used to adjust the droplets spacing without changing the droplet diameter. The system is comparable to the one described by Nguyen and Dunn-Rankin [15] and Lavieille et al. [14]. The undeviated droplets stream features a different droplet spacing from that of the initial jet, depending on the number of the initially charged droplets. With this device, it is possible to eliminate 2 out of 3,3 out of 4 , 4 out of 5 droplets or more.

Another advantage of this configuration is that the time elapsed from the injector exit can be easily determined by measuring the droplets' local velocity.

The fuel was ethanol seeded with a small fraction of rhodamine $\mathrm{B}$ and sodium hydroxide $(\mathrm{NaOH})$. These two additives, in very low concentration, are used for the temperature measurements by the two-color LIF [16].

\section{Experimental techniques}

\subsection{Droplet mass variation measurement using PDA}

The PDA (particle dynamic analyzer) is widely used in sprays, to obtain statistical properties related to the droplet size distribution. In the present study, the PDA was used to determine the diameter evolution of a droplet as a function of the distance from the ignition point (i.e. as a function of time). The measurement of the mass flowrate must be as accurate as possible, since the evaporation heat flux is the product of this parameter times the latent heat of vaporization, and is therefore a critical term in the energy budget.

The principles of PDA consist in analyzing Doppler bursts received by at least two photodetectors directed slightly differently; a third detector is usually added allowing removal of the $2 \pi$ ambiguity. Measurements were operated in refraction mode since the droplets are transparent and the signal level is increased. In simplified form, the phase difference $\varphi_{i j}$ between Doppler bursts received by two spatially shifted detectors (i) and $(j)$ can be written:

$\varphi_{i j}=\varphi_{i}-\varphi_{j}=P_{i j} D$

where $P_{i j}$ is the phase factor that depends on the PDA optical arrangement.

One problem to avoid as much as possible is the trajectory ambiguity, which is characterized by erroneous measurements of the droplets diameter, depending on the position of the droplet trajectory in the measurement volume. This effect is related to the Gaussian shape of the laser beams and is only possible when the particle size is of the order or larger than the laser beam width (Sankar et al. [17], Gréhan et al. [18], Albrecht et al. [19]). The trajectory effect is characterized by the contributions from both the desired scattering order and an unwanted scattering order (the reflection mode in the present case) that will be received with a time displacement. The distortion of the Doppler signal due the unwanted scattering order is the cause of an erroneous interpretation of the phase difference between Doppler bursts received by the detectors. The risk of error is particularly high in the case of linear monodisperse droplets stream since the trajectory of the droplets is very stable and the droplets are relatively large in the present case, compared to the width of the laser beam.

The selected optical arrangement is as a trade-off between two criteria, the first one being the minimization of the trajectory effect, the second one to preserve a good sensitivity to the size variation measurement, i.e. a sufficiently high phase factor. The droplet sizes considered in the present study are around $100 \mu \mathrm{m}$. Among the different available optical configurations, the selected optical parameters make it possible to obtain a laser beam diameter $\delta=243 \mu \mathrm{m}$ in the measurement volume. Even with this beamwidth, the trajectory effect is likely to exist since it is commonly admit that the ratio of the measurement volume diameter to the droplet diameter must be higher than 5 to obtain a limited error.

With a scattering angle $\theta=25^{\circ}$ and for the laser wavelength $\lambda=514.5 \mathrm{~nm}$ (the green line of the argon ion laser), a sufficiently high phase factor of the order of $6 \% \mu \mathrm{m}$, can be obtained. With such a scattering angle, the phase factor depends on the liquid refractive index. According to the variation of the ethanol refractive index in the range $10-70{ }^{\circ} \mathrm{C}$, the predicted phase factor varies from about $6.36 \% \mathrm{~m}$ to $6.156 \% \mu \mathrm{m}$. Since the droplet temperature will be measured by the two-color LIF technique, the phase factor will be re-adjusted at each measurement step in order to improve the measurement accuracy.

An accurate value of the phase factor was determined by implementing an initial calibration process with the use of the monodisperse injector. For such an injector, near the injection point, the droplet diameter $D_{\mathrm{i}}$ is directly related to the fuel flowrate $Q$, when monodisperse droplets are obtained at the frequency $f$ : 


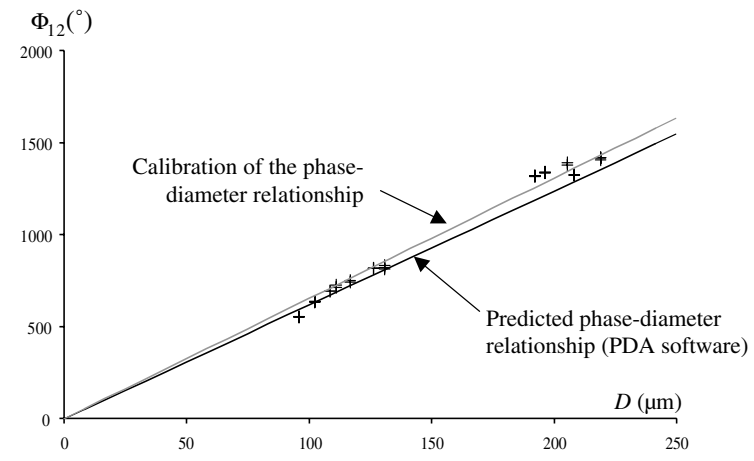

Fig. 2. Calibration of the PDA.

$D_{\mathrm{i}}=\left(\frac{6 Q}{\pi f}\right)^{1 / 3}$

The calibration process was implemented under isothermal conditions in order to limit the evaporation. The phase difference $\varphi_{12}$, taking into account the $2 \pi$ jumps, is plotted in Fig. 2 as a function of the droplet diameter given by Eq. (3). As expected, the phase difference $\varphi_{12}$ is a linear function of the diameter and the phase factor is $6.54 \% \mu \mathrm{m}$ at $18^{\circ} \mathrm{C}$, which differs from the predicted one.

The effect of the trajectory ambiguity has been also investigated on a particularly stable monodisperse droplet stream, in order to avoid as much as possible random motions of the droplets in the measurement volume. The monodisperse jet was moved in the measurement volume in the $(x, z)$ plane, as illustrated in Fig. 3. The droplet diameter, determined using an accurate measure-
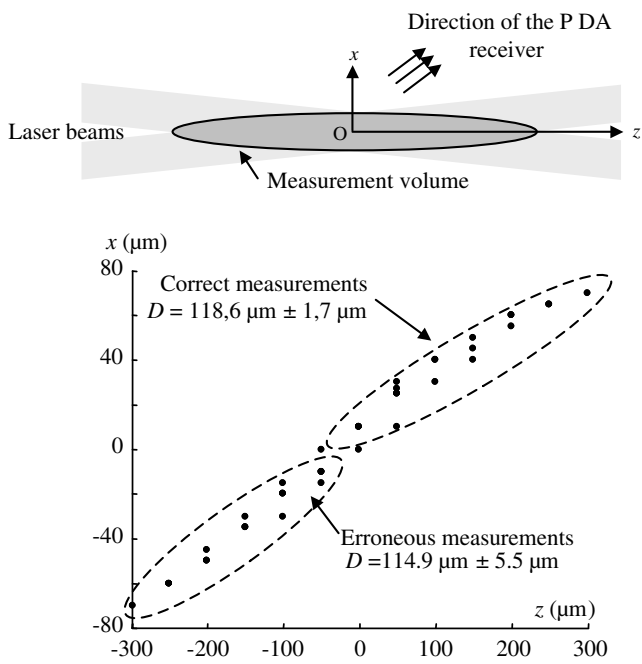

Fig. 3. Trajectory ambiguity effect for the droplet size measurement, real diameter $D=118.9 \mu \mathrm{m} \pm 0.5 \mu \mathrm{m}$. ment of the fuel flowrate is $118.9 \mu \mathrm{m} \pm 0.5 \mu \mathrm{m}$. The results of the PDA measurements are presented in the diagram of Fig. 3. The measured diameters scatter in the range $[107.9 \mu \mathrm{m} ; 122.8 \mu \mathrm{m}]$, the highest deviations from the real diameter being observed for $x<0$ and $z<0$. For $x \geqslant 0$ and $z \geqslant 0$, the mean diameter is distributed around $118.6 \mu \mathrm{m}$ with a $1.75 \mu \mathrm{m}$ RMS, which is in good agreement with the actual diameter. Indeed for $x \geqslant 0$ and $z \geqslant 0$, i.e. when the droplet stream is located on the side of the PDA receiving optics (Fig. 3), the influence of the reflected mode is minimized and then a correct diameter can be obtained. The method has been tested on an ethanol monodisperse droplet stream, injected at ambient temperature. The droplet diameter determined by a measurement of the fuel flowrate is $D=110 \mu \mathrm{m} \pm 0.5 \mu \mathrm{m}$. No significant evaporation is expected for such a jet, since the droplets at ambient temperature are quickly saturated in vapor. As seen in Fig. 4 , a rather moderate scatter can be observed, regardless of the streamwise position of the measurement point. The mean droplet diameter is distributed around $110.4 \mu \mathrm{m}$ with a $0.3 \mu \mathrm{m}$ RMS, which is in excellent agreement with the real diameter.

According to the overall sources of errors, the global uncertainty on the diameter measurement can be estimated at $\pm 1 \mu \mathrm{m}$, for droplets diameters around $100 \mu \mathrm{m}$.

The droplet velocity can be measured simultaneously by processing the Doppler frequency of the bursts; the uncertainty on the velocity measurement is estimated at $1 \%$.

\subsection{Temperature measurements using two-colors laser-induced fluorescence}

The two-colors laser-induced fluorescence technique uses the fluorescent properties of an organic dye added to the liquid fuel, induced by a suitable laser excitation. The method, developed first by Lavieille et al. [13], has been successfully applied to mean temperature measurements

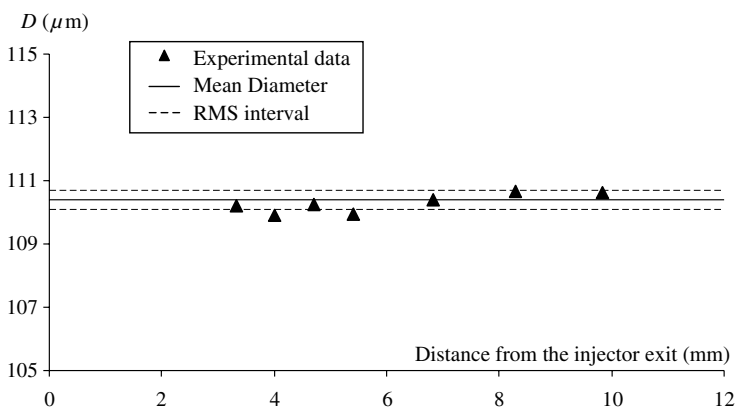

Fig. 4. Validation test of the diameter measurement method (monodisperse droplet stream injected at the ambient temperature). 


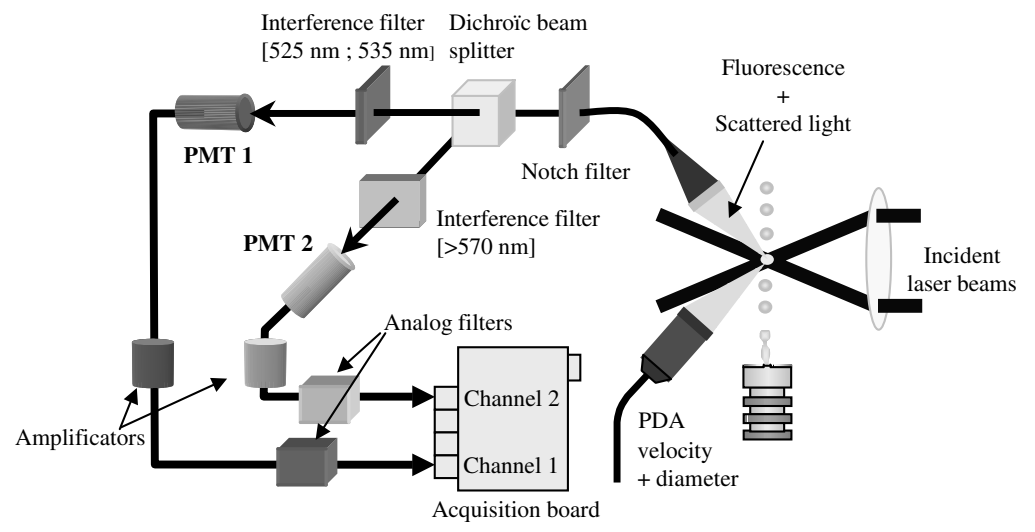

Fig. 5. Two-color laser-induced fluorescence experimental set-up.

of single droplets in a linear stream, in evaporation and combustion regimes ([12-14]). Generally speaking, the fluorescence signal of a droplet depends on the added tracer concentration, on the volume corresponding to the intersection between the incident laser beam, the droplet and the solid angle of detection. The measurement volume is then modified when the droplets are crossing the intersection of the beams. The temperature dependence is encountered for only a few tracers like rhodamine B. In order to remove the dependencies of all the parameters except the temperature, the fluorescence intensity is detected on two spectral bands for which the temperature sensitivity is highly different (Fig. 5). This ratio of the fluorescence signal measured on the two spectral bands of detection depends only on temperature. More technical details about the two-color laser-induced fluorescence can be found in [12-14].

The same laser source (argon ion laser tuned to the line $\lambda=514.5 \mathrm{~nm}$ ) and same measurement volume are used for both phase Doppler and two-colors laserinduced fluorescence measurements. The measurement volume corresponds to the intersection area of the two laser beams, generated by the PDA system. Two kinds of collection optics focus onto the intersection area of the two intersecting laser beams (Fig. 5):

- the PDA receiver, placed at a scattering angle of $25^{\circ}$ of the laser beams bisecting line,

- the detection optics of the fluorescence, which are fiber-coupled with the fluorescence processing device ([10], [11]) placed at right angles to the incident laser beam (see Fig. 5).

Due to the large diameter of the laser beams in the probe volume, the major part of the droplet can be illuminated by the laser beams. The averaging of the fluorescence signal over the complete droplet transit time in the measurement volume makes it possible to obtain the droplet mean temperature $T_{\mathrm{m}}$. By evaluating the different sources of potential errors, i.e. initial calibration of the fluorescence signal as a function of the temperature, non-linearity of the detection apparatus, the uncertainty on the temperature measurement can be estimated to be $\pm 1^{\circ} \mathrm{C}$.

\section{Energy budget in a combusting, monodisperse stream}

The droplet enthalpy evolution is directed by the variation of the heat fluxes resulting from forced convection with the surrounding gaseous environment, vaporization and radiation. The radiation effects are often neglected in the budget ([20], [21]), since the droplets are supposed to behave as a transparent medium. The case of a moving evaporating droplet with a regressing surface will be considered. Assuming that the local heat flux exchanged at the droplet surface is homogeneous, the overall budget equation can be summarized by:

$\Phi_{\mathrm{C}}+\Phi_{\mathrm{R}}=\Phi_{\text {vap }}+Q_{\mathrm{L}}$

where $\Phi_{\mathrm{C}}$ is the convective heat flux exchanged with the gaseous environment, $\Phi_{\mathrm{R}}$ is the radiative heat flux, $Q_{\mathrm{L}}$ is the heat flux entering into the liquid phase and $\Phi_{\text {vap }}$ is the heat flux due to vaporization defined by:

$\Phi_{\text {vap }}=L_{\mathrm{v}} \dot{m}$

In this expression, the fuel vapor flowrate $\dot{m}$ is of positive sign and $L_{\mathrm{v}}$ is the latent heat of vaporization.

The determination of the radiative heat flux is a particularly complex problem. The estimation of this flux requires the knowledge of the spectral luminance of the flame as well as the properties of absorption of the droplets which depend on the chemical composition of the fuel and on the droplet size. The thermal effects of radiations may be important in the case of opaque droplets behaving as a black body, but it may be considerably limited in the case of semi-transparent droplets according to Dombrovsky et al. [22]. The particular case of ethanol droplets was studied in detail 
by Elperin and Krasovitov [5]. These authors underlined that the effect of radiation is significant only in the case of large droplets, since the received radiative flux increases with the surface of the droplet. For small droplets' size (around $100 \mu \mathrm{m}$ ) and for an ambient temperature corresponding to the case of combusting ethanol vapor, the increase of the evaporation rate related to the radiation transfers is negligible. Therefore, the work developed in the present paper will be developed under this assumption.

The convective heat flux exchanged with the surrounding gas phase at the droplet surface is defined by:

$\Phi_{\mathrm{C}}=h S\left(T_{\mathrm{amb}}-T_{\mathrm{S}}\right)$

where $h$ is the convective heat transfer coefficient defined by:

$h=\frac{N u \lambda_{\mathrm{g}}}{D}$

$S$ is the droplet surface and $T_{\mathrm{amb}}$ is the ambient temperature corresponding to the gas phase temperature surrounding the droplet which characterizes the heat exchanged between the droplet and its environment, $\lambda_{\mathrm{g}}$ is the thermal conductivity of the surroundings. $N u$ is Nusselt number, which is defined by:

$N u=\frac{\left.D \frac{\partial T_{\mathrm{g}}}{\partial r}\right|_{\mathrm{S}}}{\left(T_{\mathrm{amb}}-T_{\mathrm{S}}\right)}$

The Nusselt number can be determined using Eqs. (4)-(7),

$\dot{m}=\pi D \rho_{\mathrm{g}} a_{\mathrm{g}} B_{\mathrm{T}} N u$

where $a_{\mathrm{g}}=\frac{\lambda_{\mathrm{g}}}{\rho_{\mathrm{g}} \mathrm{C}_{\mathrm{pg}}}$ is the gas thermal diffusivity and $B_{\mathrm{T}}$ is the Spalding heat transfer number defined by:

$B_{\mathrm{T}}=\frac{\mathrm{C}_{\mathrm{pg}}\left(T_{\mathrm{amb}}-T_{\mathrm{S}}\right)}{L_{\mathrm{v}}+Q_{\mathrm{L}} / \dot{m}}$

At the droplet surface, the fuel vapor flowrate conservation equation may be written by:

$\dot{m}=\dot{m} Y_{\mathrm{K}, \mathrm{S}}-\left.\pi D^{2} \rho_{\mathrm{g}} D_{\mathrm{g}} \frac{\mathrm{d} Y_{\mathrm{k}}}{\mathrm{d} r}\right|_{\mathrm{S}}$

The Sherwood number, defined by:

$$
S h=\frac{-\left.D \frac{\partial Y_{\mathrm{K}}}{\partial r}\right|_{\mathrm{S}}}{\left(Y_{\mathrm{K}, \mathrm{S}}-Y_{\mathrm{K}, \mathrm{amb}}\right)}
$$

can be introduced into Eq. (11):

$\dot{m}=\pi D \rho_{\mathrm{g}} D_{\mathrm{g}} B_{\mathrm{M}} S h$

where $B_{\mathrm{M}}$ is the Spalding mass transfer number defined by:

$B_{\mathrm{M}}=\left(\frac{Y_{\mathrm{K}, \mathrm{S}}-Y_{K, \mathrm{amb}}}{1-Y_{\mathrm{K}, \mathrm{S}}}\right)$
The comparison between the two expressions of the fuel vapor flowrate (Eqs. (9) and (13)) leads to the following non-dimensional energy budget:

$B_{\mathrm{T}} N u=L e B_{\mathrm{M}} S h$

where $L e$ is the Lewis number defined by $L e=\frac{D_{\mathrm{g}}}{a_{\mathrm{g}}}$.

The experimental characterization of the heat and mass transfer parameters, i.e. the Nusselt and Sherwood numbers, requires the determination of the time evolution of the droplet mass, the surface temperature if the thermal equilibrium is not reached, the gas phase temperature $T_{\mathrm{amb}}$ and also the droplet mean temperature $T_{\mathrm{m}}$ in order to evaluate the heat flux $Q_{\mathrm{L}}$ entering into the droplet. The heat flux $Q_{\mathrm{L}}$ transferred into the droplet contributes mainly to an increase of the mean temperature. The flux of enthalpy lost by the surface regression caused by the evaporation must be also considered. According to Lavieille et al. [14] and Castanet et al. [12], $Q_{\mathrm{L}}$ can be evaluated by:

$Q_{\mathrm{L}}=m \mathrm{C}_{\mathrm{pl}} \frac{\mathrm{d} T_{\mathrm{m}}}{\mathrm{d} t}+\mathrm{C}_{\mathrm{pl}}\left(T_{\mathrm{S}}-T_{\mathrm{m}}\right) \dot{m}$

\section{Experimental results}

\subsection{Measurement process}

A wide range of aerothermal conditions was tested. Two kinds of processes, depending on the desired distance parameter, were implemented.

The first one is used for distance parameters ranging typically from 2 to 4 . The injection pressure, i.e. the fuel flowrate and subsequently the injection velocity is first fixed and the frequency of the piezoceramic is adjusted to obtain the monodisperse injection conditions. The initial distance parameter is given by:

$C_{\mathrm{i}}=\frac{V_{\mathrm{i}}}{f D_{\mathrm{i}}}$

The droplet diameter $D_{\mathrm{i}}$ at the injection is directly related to the fuel flowrate $Q$ and piezoceramic frequency $f$ according to Eq. (3). The initial velocity $V_{\mathrm{i}}$ depends on the fuel flowrate and the injector hole diameter. This process was repeated in order to obtain various aerothermal conditions.

In the second process, the electrostatic deviator was used. Monodisperse injection conditions were established without electrostatic deviation by a fine adjustment of the injection velocity and piezoceramic frequency. The initial droplet diameter was fixed and the distance parameter was modified by removing a number of periodically deviated droplets. Higher distance parameters, typically ranging from 6 to 18 , are attainable using this second process. 


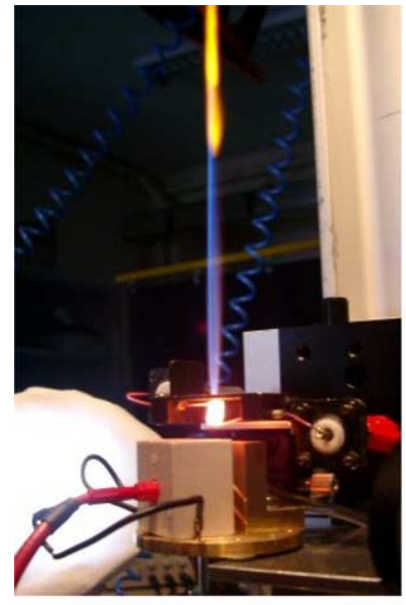

$$
C_{0}=6,6
$$

Fig. 6. Pictures of the monodisperse droplet stream in combustion for two distance parameters.

Qualitatively the first experiments showed that the flame front appeared closer to the droplet stream and the flame length shortened when the distance parameter was increased (Fig. 6). If $C>19$, the flame extinguishes for droplets moving between 2 and $10 \mathrm{~m} / \mathrm{s}$.

An investigation of each combusting droplet stream was performed step by step, from the ignition point to the top of the flame: the mean droplet temperature, the droplet velocity and the droplet diameter were measured simultaneously at each point.

The origin of time was fixed at the point of ignition. The time elapsed from the origin to the $j+1$ th point can be calculated by the recursive relationship:

$t_{j+1}=t_{j}+\frac{L_{j+1}-L_{j}}{\left(V_{j+1}+V_{j}\right) / 2}$

where $L_{j}$ is the distance of the $j$ th point from the origin and $V_{j}$ is the velocity measured at the $j$ th point. Thus, the droplet diameter and temperature evolutions can be monitored as a function of time.

\subsection{Measurement results}

Only a full set of raw experimental data will be presented in this paragraph, corresponding to a monodisperse stream with electrostatic deviation and subsequently a range of increasing distance parameters. The droplet diameter at injection is $D_{\mathrm{i}}=91 \mu \mathrm{m}$ and the velocity at injection is $V_{\mathrm{i}}=7.5 \mathrm{~m} / \mathrm{s}$.

For a given distance parameter $C$, the velocity of the droplets decreases linearly due to gravity and drag forces. Furthermore, the slope of decrease is influenced by the distance parameter, the velocity decrease becoming more pronounced as the distance parameter is increased (Fig. 7). This behavior is expected and has

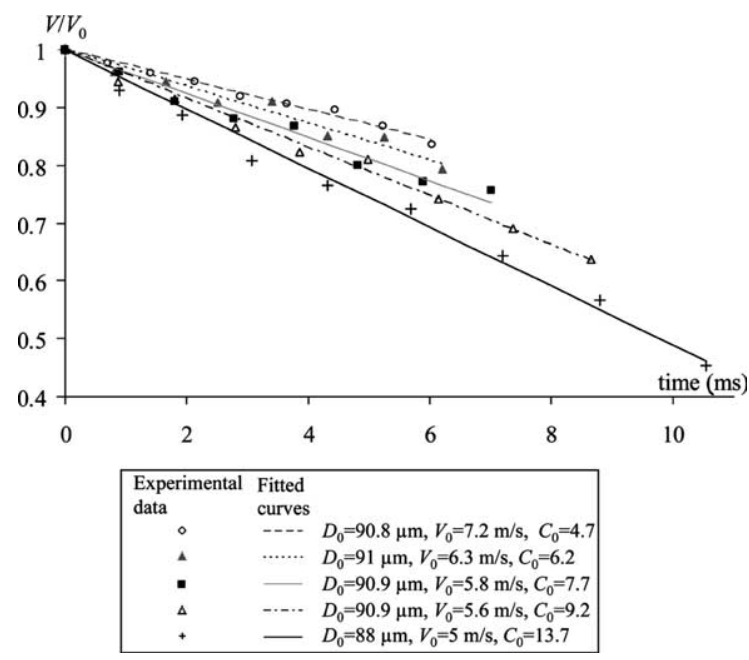

Fig. 7. Temporal evolution of the velocity for different distance parameters obtained by successive electrostatic deviation of a monodisperse droplet stream $(D=91 \mu \mathrm{m}, V=7.5 \mathrm{~m} / \mathrm{s})$.

been already observed in similar situations [23]. The evolution of the squared droplet diameter is presented in Fig. 8: the diameter decrease follows roughly a $D^{2}$ law and the regression rate increases with the distance parameter. However, the direct raw data analysis must be thorough, since the diameter regression rate should also depend on the droplet Prandtl, Schmidt and Reynolds numbers ([3], [23]).

The mean droplet temperature evolution is presented for the same conditions in Fig. 9. Two phases are clearly observable: a first phase corresponding to the intense heating of the droplet by forced convection due to the high level of the background temperature. At the end of this phase, the droplet temperature attains an equilibrium temperature corresponding to a wet bulb temperature, lower than to the boiling temperature of the fuel $\left(78^{\circ} \mathrm{C}\right.$ in the case of ethanol). During this phase, the droplets vaporize at constant temperature.

The equilibrium temperature for the different tested injection conditions ranges from $57^{\circ} \mathrm{C}$ to $62^{\circ} \mathrm{C}$. The differences observed are moderate but significant since the uncertainties on the temperature measurement are not more than $1^{\circ} \mathrm{C}$. The evolution of the normalized temperature defined by $\frac{T-T_{0}}{T_{\mathrm{eq}}-T_{0}}$ seems not to be influenced by the distance parameter for droplets injected with the same diameter and velocity. It is possible to interpret this observation by assuming that the surface attains the equilibrium temperature very quickly after ignition. Under this assumption, the droplet heating is only a function of the intensity of the internal fluid motions within the droplet which contribute to enhance the heat transfer in the droplet. This intensity is strongly related to the droplet Peclet number that depends on droplet 


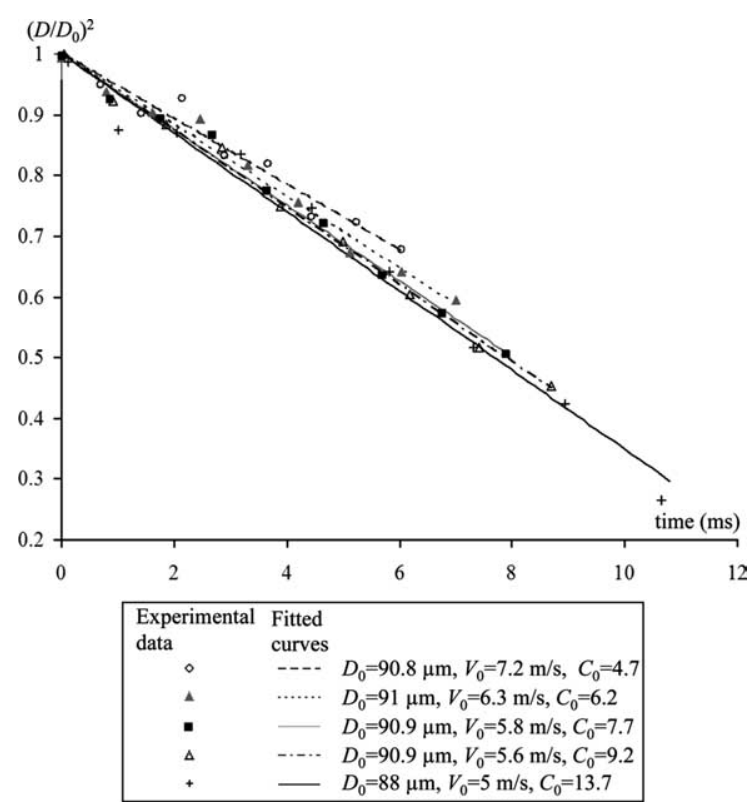

Fig. 8. Temporal evolution of the squared diameter for different distance parameters obtained by successive electrostatic deviation of a monodisperse droplet stream $(D=91 \mu \mathrm{m}$, $V=7.5 \mathrm{~m} / \mathrm{s})$.

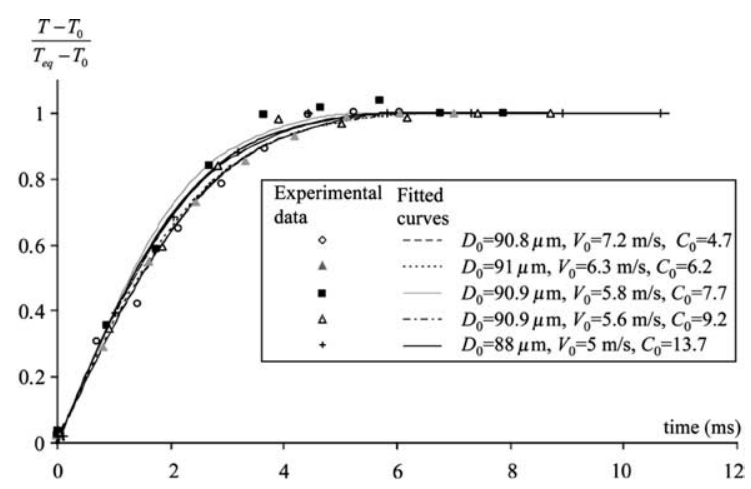

Fig. 9. Temporal evolution of the temperature for different distance parameters obtained by successive electrostatic deviation of a monodisperse droplet stream $(D=91 \mu \mathrm{m}, \quad V=$ $7.5 \mathrm{~m} / \mathrm{s})$.

diameter and velocity [2]. These parameters are only weakly modified during the heating phase, leading to a low dependence of the Peclet number on the distance parameter.

\subsection{Fluxes evaluation}

A coarse estimation of the heat flux $Q_{\mathrm{L}}$ can be obtained by replacing the surface temperature $T_{\mathrm{S}}$ by the measured temperature at equilibrium in the expression 16. The budget Eq. (4) allows estimation of the convec- tive heat flux $\Phi_{\mathrm{C}}$. Fitted profiles of the diameter and mean temperature evolution in good accordance with the experimental data are used to estimate the fuel vapor flowrate $\dot{m}$ and the time derivative of the temperature $\mathrm{d} T_{\mathrm{m}} / \mathrm{d} t$ required for flux evaluation. In particular, the slope $K$ corresponding to the combustion rate of the $D^{2}$ law is calculated:

$D^{2}(t)=D^{2}(t=0)-K t$

All the heat fluxes of Eq. (4) are plotted in Fig. 10, for various examples of initial conditions, i.e. the same diameter and injection velocity but different distance parameters. As expected, the heating flux $Q_{\mathrm{L}}$ tends to zero when the droplet temperature attains its equilibrium value. Moreover, this term seems almost insensitive to the distance parameter variations, as noticed for the droplet temperature evolution. A noticeable decrease of the evaporation flux in time can be observed, probably due to the saturation by vapor of the droplet surface. The strong influence of the distance parameter on this flux may be pointed out for the smallest distance parameters (coarsely less than 8), but this effect tends to vanish for higher distance parameters, which has been already mentioned in several works ([23], [24] and [6]). In parallel, the convective heat flux exchanged with the gaseous phase decreases as the droplet temperature increases and becomes equal to the evaporation flux in the equilibrium phase. The distance parameter dependence observed for the vaporization flux has the same consequence on the convective heat flux. The majority of the heat transferred from the hot gaseous environment contributes to the vaporization since the heat flux $Q_{\mathrm{L}}$ is always significantly smaller than the vaporization flux $\Phi_{\text {vap }}$.

Introducing the uncertainties on the measurements of the droplet mean temperature, diameter and velocity allows evaluating the global uncertainties on the different fluxes. The uncertainties are represented in Fig. 11 only for the case $C=7.7$, but are representative of the other cases.

\subsection{Nusselt and Sherwood numbers}

With the help of the experimental determination of the mass flowrate $\dot{m}$, the Sherwood number can be determined according to Eq. (13). The fuel mass fraction at the droplet surface $Y_{K, S}$ is directly related to the droplet surface temperature, by assuming the fuel liquid-vapor equilibrium at the droplet surface:

$P_{\mathrm{S}}\left(T_{\mathrm{S}}\right)=P \frac{\frac{Y_{\mathrm{K}, \mathrm{S}}}{M_{\mathrm{K}}}}{\frac{Y_{\mathrm{K}, \mathrm{S}}}{M_{\mathrm{K}}}+\frac{1-Y_{\mathrm{K}, \mathrm{S}}}{M_{\text {air }}}}$

where $P_{\mathrm{S}}\left(T_{\mathrm{S}}\right)$ is the vapor saturating pressure at the droplet surface temperature $T_{\mathrm{S}}$. The droplet surface temperature $T_{\mathrm{S}}$ corresponds to the measured temperature if 


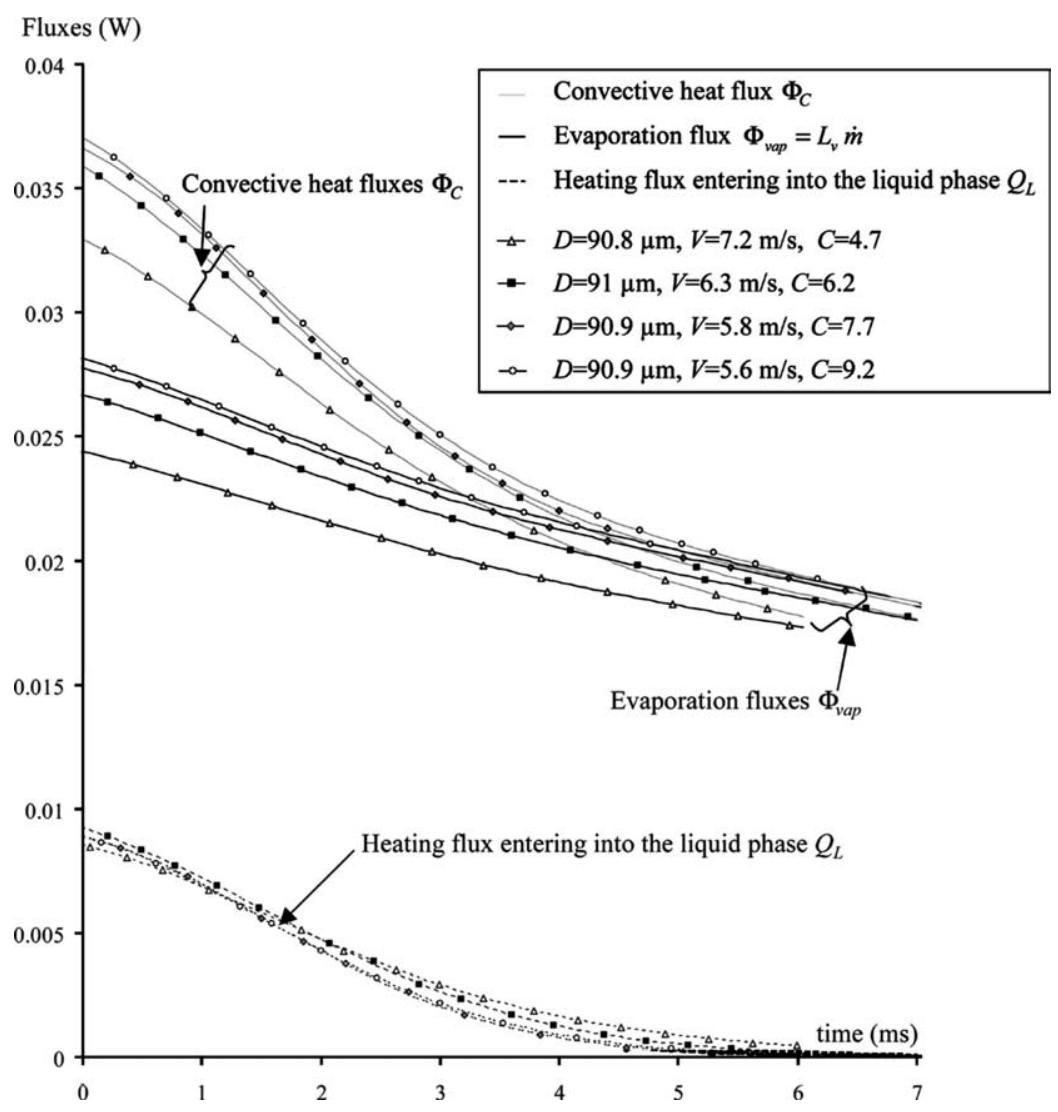

Fig. 10. Energy shares for different distance parameters obtained by successive electrostatic deviation of a monodisperse droplet stream $(D=91 \mu \mathrm{m}, V=7.5 \mathrm{~m} / \mathrm{s})$.

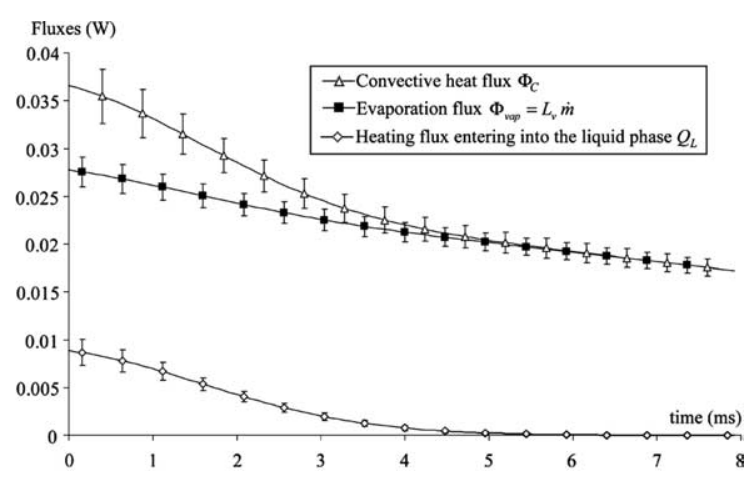

Fig. 11. Energy shares and uncertainties representation for the different fluxes in the particular case $(D=90.9 \mu \mathrm{m}, V=5.8 \mathrm{~m} / \mathrm{s}$, $C=7.7)$.

the droplet is at equilibrium. In the heating phase, it will be assumed that the surface has already reached the equilibrium temperature.

All the physical properties of the gaseous phase are updated and calculated at each time step at the reference state defined by the " $1 / 3$ " law [25] applied to the fuel mass fraction and to the gas phase temperature:
$T_{\mathrm{ref}}=\frac{1}{3} T_{\mathrm{amb}}+\frac{2}{3} T_{\mathrm{S}} \quad Y_{\mathrm{K}, \mathrm{ref}}=\frac{1}{3} Y_{\mathrm{K}, \infty}+\frac{2}{3} Y_{\mathrm{K}, \mathrm{S}}$

The problem is to select properly the ambient temperature $T_{\mathrm{amb}}$ and the surface temperature $T_{\mathrm{S}}$. The same problem is also present in the calculation of the Nusselt number, which is evaluated from the experimental convective heat flux, the surface temperature and also the ambient temperature according to the expressions 6 and 7. The ambient temperature is not clearly defined in combustion and is likely to vary during the transit of the droplets in the flame, as well as the surface temperature. The surface temperature is approximated by the equilibrium temperature which can be easily tracked on the experimental profiles. Practically, it means that the surface is expected to attain the equilibrium temperature very quickly after ignition. The ambient temperature can be also estimated from the equilibrium temperature. For combustion conditions of ethanol, the Lewis number of the ethanol vapor in air is very close to 1 . Consequently, the heat and mass transfer processes present similarities. The droplet surface constitutes a source of vapor and a sink of heat, whereas the 
flame front is a sink of fuel vapor and a source of heat. For these reasons, the Nusselt and Sherwood numbers are expected to be equal and are supposed to be modified identically by the effects of the interactions. This assumption appears reasonable since no influence of the distance parameter is observed on the heating profile of the droplets (Fig. 9). The non-dimensional energy budget (Eq. (15)) can be rewritten as a simple equality between the Spalding numbers $B_{\mathrm{M}}$ and $B_{\mathrm{T}}$ :

$B_{\mathrm{T}}=B_{\mathrm{M}}$

According to the expressions 10 and 14, the Spalding numbers depend only on the ambient temperature and on the droplet surface temperature at the equilibrium. The Eq. (22) allows calculation of the ambient temperature, if the equilibrium droplet temperature is known. According to Godsave [26] and Spalding [27], the ambi-

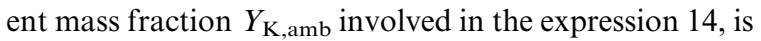
defined in combustion by:

$Y_{\mathrm{K}, \mathrm{amb}}=-\frac{M_{\mathrm{K}}}{v M_{\mathrm{Ox}}} Y_{\mathrm{Ox}, \infty}$

where $Y_{\mathrm{Ox}, \infty}$ is the oxidizer mass fraction far from the flame front and $v$ is a stoichiometric coefficient. ${ }^{1}$

The solutions of Eq. (22), expressing the ambient temperature as a function of the equilibrium droplet temperature, are represented in Fig. 12. The measured equilibrium temperatures range between $57^{\circ} \mathrm{C}$ and $62{ }^{\circ} \mathrm{C}$, which correspond to ambient temperatures ranging between $800{ }^{\circ} \mathrm{C}$ and $1100^{\circ} \mathrm{C}$ in combustion. Thus, for each investigated case, different ambient temperature are applied, according to the measured equilibrium temperature reported in Table 1.

\subsection{Influence of the interactions}

The quantification of the interaction phenomena remains difficult, since the Nusselt and Sherwood numbers depend also on the droplet Reynolds, Prandtl and Schmidt numbers additionally to the Spadling number. In a quasi-steady approach of the evaporation and according to the thin film theory [2], the expressions of the Nusselt and Sherwood numbers for an isolated evaporating moving droplet are:

$$
\begin{aligned}
& N u_{\text {iso }}=\left(\frac{\ln \left(1+B_{\mathrm{T}}\right)}{B_{\mathrm{T}}}\right)\left(2+k \frac{\operatorname{Re}_{\mathrm{ref}}^{1 / 2} \operatorname{Pr}_{\mathrm{ref}}^{1 / 3}}{F\left(B_{\mathrm{T}}\right)}\right) \\
& S h_{\text {iso }}=\left(\frac{\ln \left(1+B_{\mathrm{T}}\right)}{B_{\mathrm{T}}}\right)\left(2+k \frac{R e_{\mathrm{ref}}^{1 / 2} S c_{\mathrm{ref}}^{1 / 3}}{F\left(B_{\mathrm{M}}\right)}\right)
\end{aligned}
$$

\footnotetext{
${ }^{1} \mathrm{CH}_{3} \mathrm{CH}_{2} \mathrm{OH}+3 \mathrm{O}_{2} \rightarrow 2 \mathrm{CO}_{2}+3 \mathrm{H}_{2} \mathrm{O} \quad(v=3$ in the case of ethanol).
}

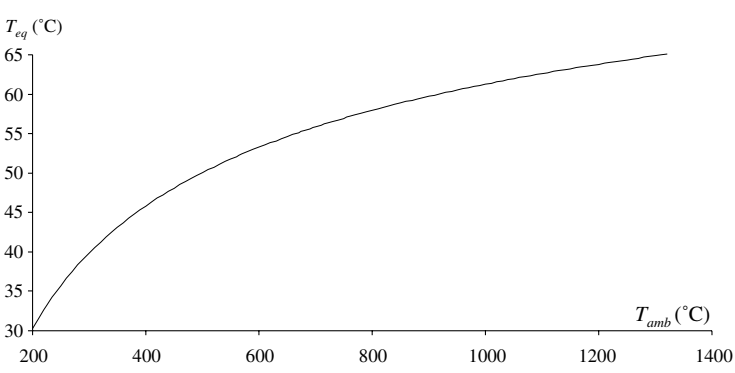

Fig. 12. Relationship between the ambient temperature and the droplet equilibrium temperature for combusting droplets of ethanol.

where $k=0.6$ is chosen according to the Ranz-Marshall correlation [28].

$R e_{\text {ref }}$ is the droplet Reynolds number calculated in the reference state. Both gas phase dynamic viscosity $\mu_{\text {ref }}$ and density $\rho_{\text {ref }}$ are also calculated at the reference temperature according to the " $1 / 3$ " law following Eq. (21). For the dynamic viscosity of the fuel-air mixture, the Wike relationship [29] is used. $P r_{\text {ref }}$ and $S c_{\text {ref }}$ are respectively the Prandtl and Schmidt numbers calculated in the reference state. $F(B)$ is a function introduced by Abramzon and Sirignano [2] which should be applied to the thin film surrounding the moving droplet in order to take into account evaporation, since the fuel vapor flow tends to modify the convective transport around the droplet:

$F(B)=(1+B)^{0.7} \frac{\ln (1+B)}{B}$

The ratio between the experimental Nusselt number $N u$ and the Nusselt number of the isolated droplet $N u_{\text {iso }}$

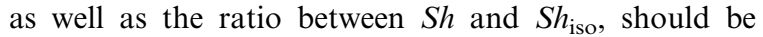
representative of the interactions effects. The ratios $N u / N u_{\text {iso }}$ and $S h / S h_{\text {iso }}$ are plotted in Figs. 13 and 14 respectively as a function of the distance parameter for about 15 injection conditions summarized in Table 1.

Each segment corresponds to the complete exploration in time of one jet. The exploration is stopped either at the top of the flame or when the random motions of the droplets make the measurement impossible. A significant variation of the Nusselt number can be observed during the heating phase. In particular, the ratio $N u / N u_{\text {iso }}$ decreases during the heating phase of the droplets because the ambient temperature implemented in the calculation of the Nusselt number is underestimated. The gas phase temperature in the vicinity of the droplets is likely to decrease as a function of time due to the flame broadening, but in the present case the ambient temperature is calculated only once from the droplet equilibrium temperature. As a consequence, the end value of the ratio $N u / N u_{\text {iso }}$ is more representative for the comparison to the case of the isolated droplet. A similar kind of observation can be made for the Sherwood number, since the surface temperature is also varying during the droplet lifetime in the flame. 
Table 1

Aerothermal parameters of the monodisperse droplet streams in combustion (all the parameters are given just after ignition except the Nusselt and Sherwood numbers, which are given in the equilibrium phase)

\begin{tabular}{lllllll}
\hline$D_{0}(\mu \mathrm{m})$ & $V_{0}(\mathrm{~m} / \mathrm{s})$ & $T_{0}\left({ }^{\circ} \mathrm{C}\right)$ & $C_{0}$ & $R e_{0, \text { ref }}$ & $T_{\text {eq }}\left({ }^{\circ} \mathrm{C}\right)$ & $N u=S h$ \\
\hline 108.9 & 6.7 & 37.2 & 4.5 & 20.8 & 57.5 & 1.5 \\
107.3 & 4.5 & 47.8 & 4 & 13.3 & 59 & 1.1 \\
104.5 & 8.2 & 38.4 & 4.2 & 22.7 & 60 & 2 \\
116 & 2.8 & 48.5 & 4.8 & 9.2 & 58 & 0.86 \\
90.8 & 7.2 & 29.7 & 4.7 & 18.5 & 57 & 2.3 \\
91 & 6.3 & 31.7 & 6.2 & 16.4 & 57.5 & 2.4 \\
90.9 & 5.8 & 34.6 & 7.7 & 15.1 & 57.2 & 2.6 \\
90.9 & 5.6 & 34.8 & 9.2 & 14.2 & 58 & 2.5 \\
88 & 5 & 36.5 & 13.7 & 12.6 & 57.5 & 2.5 \\
104.6 & 5.4 & 60 & 6 & 13.1 & 61.5 & 2.2 \\
101 & 4.5 & 57.4 & 10.5 & 10.6 & 61.5 & 2.2 \\
98.4 & 4.3 & 57.2 & 12.8 & 10.3 & 61 & 2.3 \\
96.9 & 4.2 & 61 & 15.2 & 9.91 & 61 & 2.2 \\
103.9 & 6.1 & 57.8 & 3.4 & 14.7 & 61.5 & 61 \\
97.5 & 4 & 61 & 16.7 & 9.4 & 6 & \\
\hline
\end{tabular}
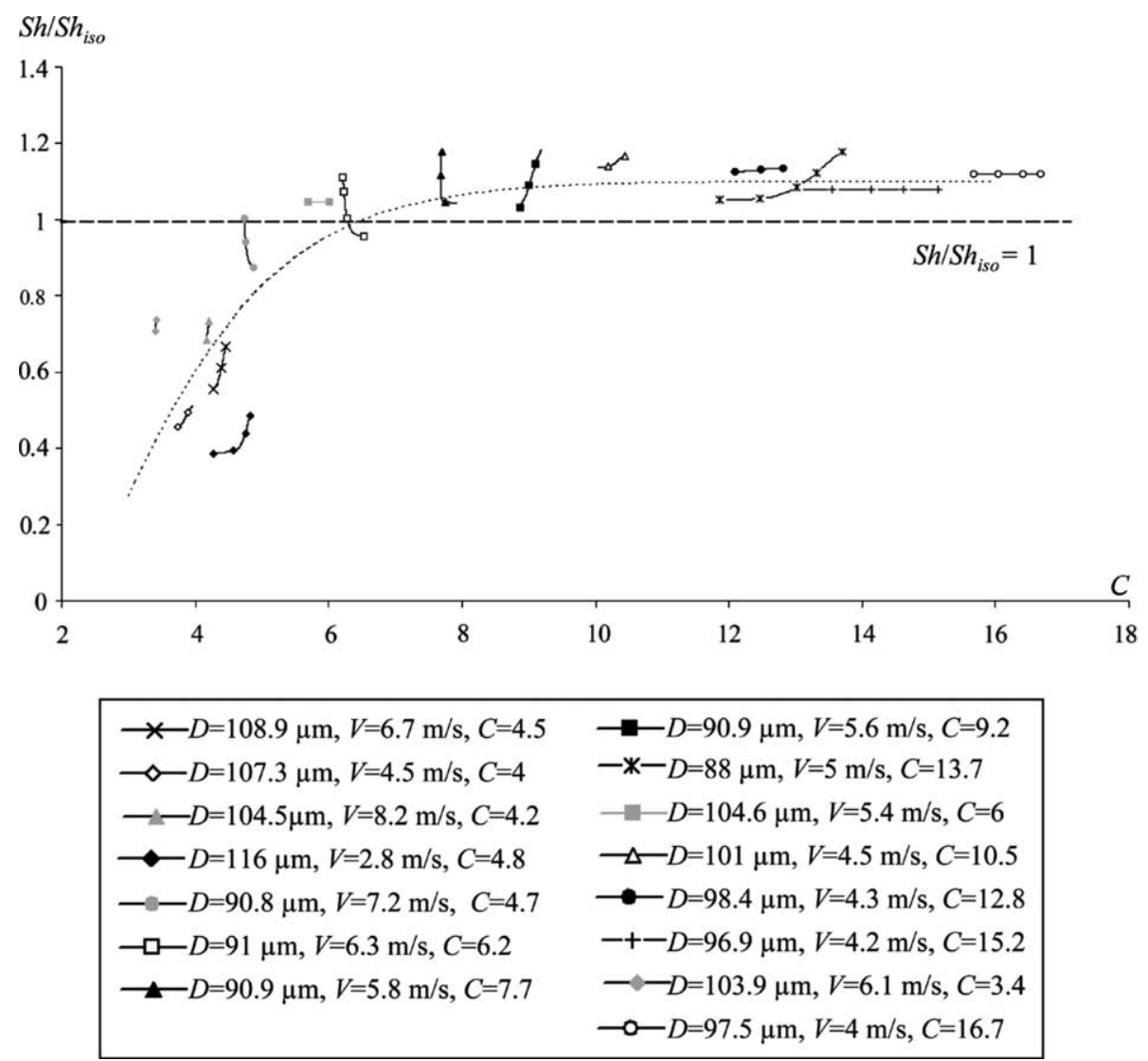

Fig. 13. Evolution of the ratio $S h / S h_{\text {iso }}$ as a function of the distance parameter.

In the light of Figs. 13 and 14, it is clear that the evolution of the normalized Nusselt and Sherwood numbers are quite similar. Beyond a distance parameter of
$C=9$, the Nusselt and Sherwood numbers remain quite insensitive to the interaction effects. The Nusselt and Sherwood numbers should tend to that of the isolated 

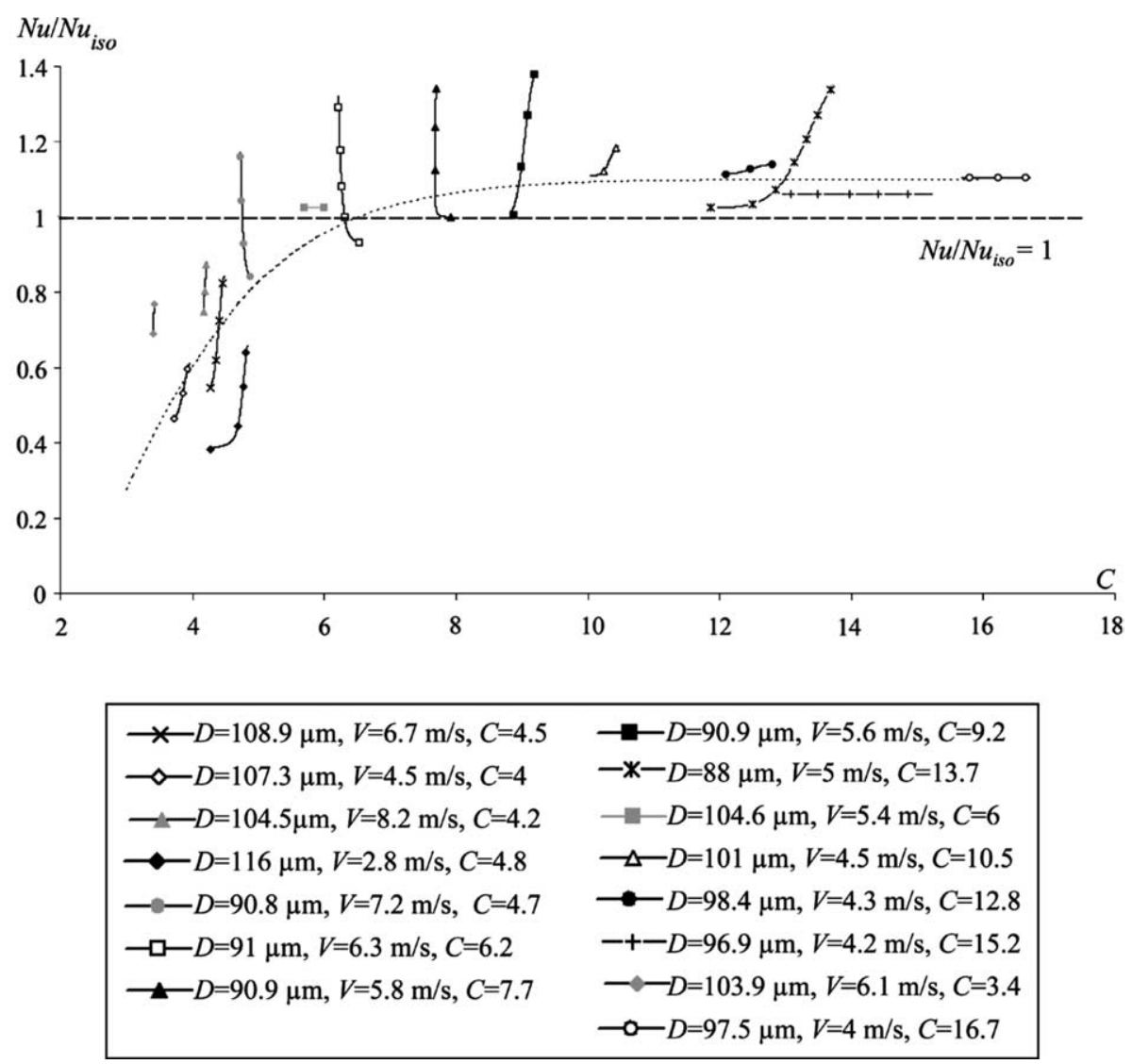

Fig. 14. Evolution of the ratio $N u / N u_{\text {iso }}$ as a function of the distance parameter.

droplet for the highest distance parameters, i.e. when the interaction phenomena become negligible. This asymptotic behavior is clearly observed in Figs. 13 and 14, although $S h / S h_{\text {iso }}$ and $N u / N u_{\text {iso }}$ seems to approach a little bit more than 1 . This difference can be partially explained by the difficulties of evaluating the various physical properties in the isolated droplet model. The gas phase density $\rho_{\text {ref }}$ and the dynamic viscosity $\mu_{\text {ref }}$ depend particularly on the reference temperature $T_{\text {ref }}$ and on the fuel mass fraction $Y_{K, \text { ref }}$ defined according to the " $1 / 3$ " law. Moreover an error of $2{ }^{\circ} \mathrm{C}$ on the equilibrium temperature shifts of about $35^{\circ} \mathrm{C}$ the reference temperature $T_{\text {ref }}$ and of $8 \%$ the fuel mass fraction $Y_{K, \text { ref }}$ which corresponds to a variation of about $10 \%$ for the Nusselt and Sherwood numbers.

For distance parameters lower than 9, the normalized Nusselt and Sherwood numbers characterize the global effect of the droplet to droplet interactions on heat and mass transfer. A clear decrease of these numbers with the distance parameter can be observed. Thus for $C=4$, heat and mass transfer between one droplet and its gaseous environment is reduced by a factor 2 , and this reduction may attain about $70 \%$ when $C=3$, although it is difficult to extrapolate for the case of the very low distance parameters, since very few experimental data are available in this region. Therefore, it is proposed to adopt a formulation of the interaction phenomena in the following way:

$\frac{N u}{N u_{\text {iso }}}=\frac{S h}{S h_{\text {iso }}}=\eta(C)$

In principle, the limit of $\eta(C)$ should be 1 for the highest distance parameters. As already commented, the experimental results show that $\eta(C)$ approaches a bit more than 1 . However, a fit of $\eta(C)$ has been proposed, by replacing the theoretical calculation of the Sherwood (or Nusselt) number by the experimental value for the highest tested distance parameter. The possible expression of the function $\eta(C)$ is given by:

$\eta(C)=\tanh (0.36 C-0.82)$

The fitted expression of $\eta(C)$ (Eq. (28)) has been also reported in Figs. 13 and 14, taking into account the difference between the theoretical calculation of the isolated Sherwood (or Nusselt) number and the experimental data, for the highest tested distance parameter.

The interaction effects are also likely to depend on the flow regime i.e. the Reynolds number. Nevertheless, 
the explored range of Reynolds numbers is too limited and therefore, in the present study, no noticeable effects on the interaction phenomena could be highlighted.

\section{Concluding remarks}

The combination of two optical techniques (two-colors LIF and PDA) allowed simultaneous measurement of the size, temperature and velocity of linearly streaming and combusting droplets.

The temperature measurements showed the existence of two phases: a transient phase of heating of the droplets followed by an equilibrium phase during which the droplets evaporate at constant temperature. Simultaneous measurements of the droplet size and mean temperature evolution allowed evaluation of the temporal behaviour of the evaporation flux and of the droplet enthalpy. The convective heat flux exchanged between the droplet and its gaseous environment is then inferred from the overall energy budget of the combusting droplet. In order to describe the aerothermal phenomena and to calculate the dimensionless Nusselt and Sherwood numbers, the knowledge of the ambient temperature, characterizing the thermal exchange with the gaseous phase, and the droplet surface temperature are necessary. Assuming that the droplet surface reaches quickly the thermal equilibrium in the hot environment of the flame, the droplet surface temperature may be comparable to the droplet equilibrium temperature easily monitored on the experimental temperature profiles. The ambient temperature corresponds to the ambient temperature that can be predicted at the thermal equilibrium by making the assumption that the Nusselt and Sherwood numbers are of comparable values.

The influence of the interaction effects on the Nusselt and Sherwood numbers was clearly quantified for distance parameters ranging between 3 and 18 . For a distance parameter lower than about 9, the reduction of the Nusselt and Sherwood numbers is significant. Beyond $C=9$, the interaction effects are almost nonexistent and the Nusselt and Sherwood numbers become then comparable with the prediction of the quasi-steady model of the isolated moving combusting droplet.

As some assumptions have been made about the evolution of the droplet surface and the gas phase temperatures, it is clear that additional data about the gas phase could be helpful. In further works, it is planned to investigate the distribution of the temperature in the gaseous phase using CARS thermometry and the fuel vapor concentration in the droplet vicinity using laser-induced fluorescence, in order to assess the ensemble of hypotheses made about the gas phase.

\section{Acknowledgements}

This work is supported by the European Community in the framework of the MUSCLES contract, Growth project GRD1-2001-40198.

\section{References}

[1] W.A. Sirignano, Fluid Dynamics and Transport of Droplets and Sprays, Cambridge University Press, 1999.

[2] B. Abramzon, W.A. Sirignano, Droplet vaporization model for spray combustion calculations, Int. J. Heat Mass Transfer 32 (1989) 1605

[3] R. Borghi, M. Destriau, La Combustion Et Les Flammes, Editions Technip, Paris, 1995.

[4] R.J. Haywood, M. Renksizbulut, G.D. Raithby, Transient deformation and evaporation of droplets at intermediate Reynolds numbers, Int. J. Heat Mass Transfer 37 (1994) 1401.

[5] T. Elperin, B. Krasovitov, Radiation, thermal diffusion and kinetic effects in evaporation and combustion of large and moderate size fuel droplets, Int. J. Heat Mass Transfer 38 (1995) 409.

[6] J.J. Sangiovanni, M. Labowski, Burning times of linear fuel droplet arrays: a comparison of experiment and theory, Combust. Flame 45 (1982) 15.

[7] T.A. Brzustowski, E.M. Twardus, S. Wojcicki, A. Sobiesiak, Interaction of two burning fuel droplets of arbitrary size, AIAA J. 17 (1979) 1234.

[8] M. Labowsky, Calculation of the burning rates of interacting fuel droplets, Combust. Sci. Technol. 22 (1980) 217.

[9] M. Marberry, A.K. Ray, K. Leung, Effect of multiple particle interactions on burning droplets, Combust. Flame 57 (1984) 237

[10] C.H. Chiang, W.A. Sirignano, Interacting, convecting, vaporizing fuel droplets with variable properties, Int. J. Heat Mass Transfer 36 (1993) 875.

[11] C.H. Chiang, W.A. Sirignano, Axisymmetric calculations of three droplet interactions, Atomization Sprays 3 (1993) 91.

[12] G. Castanet, P. Lavieille, F. Lemoine, M. Lebouché, A. Atthasit, Y. Biscos, G. Lavergne, Energetic budget on an evaporating monodisperse droplet stream using combined optical methods. Evaluation of the convective heat transfer, Int. J. Heat Mass Transfer 45 (2002) 5053.

[13] P. Lavieille, F. Lemoine, G. Lavergne, M. Lebouché, Evaporating and combusting droplet temperature measurements using two color laser induced fluorescence, Exp. Fluids 31 (2001) 45.

[14] P. Lavieille, F. Lemoine, M. Lebouché, Investigation on temperature of evaporating droplets in linear stream using two color laser induced fluorescence, Combust. Sci. Technol. 174 (2002) 117.

[15] Q.V. Nguyen, D. Dunn-Rankin, Experiments examining drag in linear droplet packets, Exp. Fluids 12 (1992) 157.

[16] P. Lavieille, F. Lemoine, M. Lebouché, G. Lavergne, Mesure de la température de gouttelettes en combustion par fluorescence induite par laser à deux couleurs: résultats préliminaires et perspectives, CR Acad. Sci. II B-Mec. 329 (2001) 557. 
[17] S.V. Sankar, K.M. Inenaga, W.D. Bachalo, Trajectory dependent scattering in phase Doppler interferometry: minimizing and eliminating sizing error. in: Proceedings of the 6th International Symposium of Applications of Laser Techniques to Fluids Mechanics, Lisbon, Portugal, 1992, paper 12.2.

[18] G. Gréhan, G. Gouesbet, A. Naqwi, F. Durst, On the elimination of the trajectory effect in phase-Doppler systems. 5th Europeans Symposium on Particle Characterization PARTEC, Nürnberg, Germany, 1992, 309.

[19] H.-E. Albrecht, M. Borys, N. Damaschke, C. Tropea, Laser Doppler and Phase Doppler Measurement Techniques, Springer, 2003.

[20] C.K. Law, Recent advances in droplet vaporization and combustion, Progr. Energy Combust. Sci. 8 (1982) 171.

[21] M.A. Silverman, D. Dunn-Rankin, Experimental investigation of a rectilinear droplet stream flame, Combust. Sci. Technol. 100 (1994) 57.

[22] L.A. Dombrosvsky, S.S. Sazhin, E.M. Sazhina, G. Feng, M.R. Heikal, M.E.A. Bardsley, S.V. Mikhalovsky, Heating and evaporation of semi-transparent diesel fuel droplets in the presence of thermal radiation, Fuel 80 (2001) 1535.
[23] J.F. Virepinte, Y. Biscos, G. Lavergne, P. Magre, G. Collin, A rectilinear droplet stream in combustion: droplet and gas phase properties, Combust. Sci. Technol. 150 (2000) 143.

[24] J.K. Leiroz, R.H. Rangel, Interaction effects during droplet-stream combustion, in: 8th international symposium on transport phenomena in combustion, San Francisco, USA, 1995.

[25] G.L. Hubbard, V.E. Denny, A.F. Mills, Droplet evaporation: effects of transients and variable properties, Int. J. Heat Mass Transfer 18 (1975) 1003.

[26] G.A.E. Godsave, Studies of the combustion of drops in a fuel spray: the burning of single drops of fuel, in : Fourth international Symposium on combustion, Williams and Wilkins, Baltimore, 1953, p. 818.

[27] D.B. Spadling, The combustion of liquid fuels, in: 4th international Symposium on combustion, Williams and Wilkins, Baltimore, 1953, p. 847.

[28] W.E. Ranz, W.R. Marshall, Evaporation from drops, Chem. Eng. Progr. 48 (1952) 141.

[29] C.R. Wilke, A viscosity equation for gas mixtures, J. Chem. Phys. 18 (1950) 517. 